\title{
Helios + Regulatory T cell frequencies are correlated with control of viral replication and recovery of absolute CD4 T cells counts in early HIV-1 infection
}

Raquel Matavele Chissumba ${ }^{1,2,3^{*}}$, Eduardo Namalango ${ }^{1}$, Vânia Maphossa ${ }^{1}$, Ivalda Macicame ${ }^{1}$, Nilesh Bhatt ${ }^{1}$, Christina Polyak ${ }^{4}$, Merlin Robbb ${ }^{4}$, Nelson Michael ${ }^{4}$, Ilesh Jani ${ }^{1}$ and Luc Kestens ${ }^{2,3}$

\begin{abstract}
Background: The acute phase of HIV infection is characterized by massive depletion of CD4 T cells, high viral plasma levels and pronounced systemic immune activation. Regulatory T cells (Tregs) have the potential to control systemic immune activation but also to suppress antigen specific $T$ and $B$ cell response. The co-expression of FoxP3 and Helios transcription factors, has been described for identification of highly suppressive Tregs. The aim of this study was to characterize the phenotype of classic Tregs during early HIV infection, and to assess the correlations between the frequencies and phenotype of Tregs with the plasma viral load, CD4 counts, immune activation and the frequency of antibodies reactive to HIV-1 proteins, measured by an immunochromatographic test.

Results: The relative frequency of classic Tregs cells in peripheral blood correlated positively with HIV viral load and immune activation of CD8 T cells, and inversely with absolute CD4 counts and development of anti-HIV antibodies in subjects with early HIV infection. However, the expression of Helios in classic Tregs was inversely correlated with viral replication and immune activation, and positively with recovery of CD4 T cell counts and appearance of antibodies reactive to HIV-1 proteins.

Conclusion: These results raise the hypothesis that classic Tregs are inefficient at controlling systemic immune activation in subjects with early HIV infection and may be associated with delayed production of antibodies against HIV proteins, delaying the control of viral replication. Conversely, Helios expressing Tregs might contribute to control of viral replication by mechanisms involving the limitation of systemic immune activation.
\end{abstract}

Keywords: Tregs, HIV early infection, Helios

\section{Background}

Regulatory T cells (Tregs) are a subset of CD4 T cells with potential to suppress the immune response, preventing excessive immune activation. Immune suppression by Tregs is mediated by soluble factors or by mechanisms requiring cell-to-cell contact [1]. To date several cells with regulatory properties have been described, but the classic Tregs are the most extensively studied.

\footnotetext{
* Correspondence: raquelmatavele@gmail.com

${ }^{1}$ Instituto Nacional de Saúde, Maputo, Mozambique

${ }^{2}$ Institute of Tropical Medicine, Department of Biomedical Sciences, Antwerp, Belgium

Full list of author information is available at the end of the article
}

Classic Tregs have been characterized by high expression of the activation marker CD25, presence of the transcription factor Foxp3 or expression of low levels of the alpha chain of Interleukin-7 (IL-7) receptor, CD127 [2]. In addition, classic Tregs can be classified as natural or induced Tregs [3, 4]. Natural Tregs emerge from the thymus with regulatory properties while induced Tregs are generated in the periphery following $\mathrm{T}$ cell activation $[5,6]$. The co-expression of the transcription factors Helios and FoxP3 identifies highly suppressive Tregs, initially identified as natural Tregs $[7,8]$.

The role of Tregs preventing the development of exacerbated reactions during the course of an immune 
response has been highlighted in autoimmune diseases [9], transplantation [10], tumors [11] and infectious diseases [7], including HIV infection [12]. In HIV infection Tregs can be beneficial by controlling chronic immune activation, but also unfavorable or even harmful by preventing development of humoral and cellular anti-HIV immune responses [12-14]. A relative increase of classic Tregs in peripheral blood has been observed in treatment-naive patients with chronic progressive HIV infection, compared with healthy uninfected individuals $[15,16]$. In addition, it has been suggested that virologic control induces a decrease in classic Tregs [17]. Little information, however, is available on the role of classic Tregs during early HIV infection, particularly in subtype $\mathrm{C}$ infections, the most prevalent HIV subtype in SubSaharan Africa and globally [18].

The early phase of HIV infection is critical as it determines the fate of the progressive infection [19-21] and the extent of virus transmission at population level $[22,23]$. The early phase starts with an exponential rise in HIV viremia, reaching a peak when acquired cellular and humoral immune responses against viral proteins emerge [23].

The aim of this study was to characterize the phenotype of Tregs in individuals with early HIV infection, and to assess how staging of the infection, based on plasma viral load, immune activation, absolute CD4 T cell counts and the frequency of antibodies reactive to HIV-1 proteins, correlates with the relative abundance and phenotype of Tregs. We report opposite correlations between total classic Tregs and those expressing Helios, during early HIV-infection, with the plasma viral load, $\mathrm{T}$ cell activation, development of anti-HIV antibodies and absolute counts of CD4 T cells.

\section{Methods}

\section{Study participants}

A total of 37 individuals, 14 with early HIV infection (< than 3 months), 8 with HIV chronic infection (> 9 months) and 15 uninfected controls were enrolled in this study. All subjects were part of a large cohort study (RV363) established for assessment of HIV incidence and associated risk factors, and willingness to participate in future HIV vaccine trials. The HIV incidence study enrolled participants in Maputo, Mozambique, at Centro de Investigação e Treino em Saúde da Polana Caniço (CISPOC) between December 2013 and November 2014. A total of 500 uninfected individuals between 18 and 35 years, at high risk for HIV infection, were enrolled for assessment of HIV incidence every three months, over a period of two years. A smaller group of HIVinfected individuals, as part of the chronic infection group, were also included in the study, as a community masking purposes. Pregnant women were excluded from the study. Peripheral blood samples were collected from
HIV early infected participants, those whom the rapid test shift from negative to positive in a period of 3 months (median) and masking group individuals for assessment of virologic and immunologic parameters. For the Tregs sub-study, peripheral blood mononuclear cells (PBMC) were available for 14 out of 19 individuals who seroconverted during the HIV incidence study. In addition, PBMC from 3 seroconverted individuals and 5 chronically infected individuals, were evaluated 9 months after the first PBMC collection and at least 2 years after infection, respectively. Randomly selected individuals who did not seroconvert and were negative for HIV, hepatitis B virus (HBV), hepatitis C virus (HCV) and syphilis were considered as control subjects (uninfected). Immunophenotyping of PBMCs was done on $22 \mathrm{HIV}$ infected individuals and 15 uninfected controls.

\section{HIV diagnosis, CD4 counts and viral load testing}

The HIV-1 diagnosis was performed on fresh venous whole blood samples, following the Mozambican national algorithm for HIV testing, which consists of two sequential rapid immunochromatographic tests for detection of anti-HIV-1/2 antibodies. Screening was first performed using the Alere Determine ${ }^{\mathrm{Tw}} \mathrm{HIV}-1 / 2$ (Alere Medical Co., Japan) rapid test. Non-reactive specimens were classified as negative. Reactive specimens were confirmed by a second rapid test, the Uni-Gold ${ }^{\text {mo }}$ HIV (Trinity Biotech PLC, Ireland). Indeterminate results, reactive for Determine but non-reactive for UniGold, were resolved by a fourth-generation ELISA, Genscreen Ultra $H I V A g-A b$ (BioRad, France). The antibody reactivity pattern for HIV-1 (p31, gp160, p24 and gp41) proteins was analyzed in all seroconverted individuals, using the Geenius HIV 1/2 Confirmatory Assay (BioRad, France) at seroconversion visit and at time of PBMC collections (Fig. 1a and b). CD4 counts were performed on whole blood cells as previously described [24]. Acquisition was performed on the four-color flow cytometer FACS CALIBUR (BD, USA). Plasma HIV-1 viral loads were determined using the COBAS AmpliPrep/COBAS TaqMan $H I V-1$ Test, $v 2$ (Roche, USA).

\section{Peripheral blood mononuclear cells immunophenotyping}

Peripheral blood mononuclear cells (PBMC) were isolated from freshly obtained heparin anti-coagulated blood, using Ficoll-Paque Plus (GE Healthcare, Sweden) and Leucosep tubes (Greiner Bio-One, German), and stored in liquid nitrogen, in a freezing media $(10 \%$ dimethyl sulfoxide (DMSO) $+90 \%$ fetal calf serum (FCS)) After thawing in a water bath at $37^{\circ} \mathrm{C}, \mathrm{PBMC}$ were washed twice in complete RPMI medium supplemented with $20 \%$ of FCS followed by $10 \%$ of FCS (R20 and R10, respectively) and viable cells were counted using the Nucleocounter NC-100 (Chemometec, Denmark). Prior 
a

\begin{tabular}{|c|c|c|c|c|c|c|c|c|}
\hline \multirow{2}{*}{ Participant } & \multicolumn{2}{|c|}{ HIV-2 } & \multicolumn{4}{|c|}{ HIV-1 } & \multirow{2}{*}{$\begin{array}{l}\text { Frequency of reactivity to } \\
\text { HIV- } 1 / 2 \text { proteins }\end{array}$} & \multirow{2}{*}{$\begin{array}{l}\text { Estimated time post } \\
\text { infection (days) }\end{array}$} \\
\hline & p36 & gp140 & p31 & gp160 & p24 & gp41 & & \\
\hline A & & & & & & & 4 & 19 \\
\hline $\mathrm{B}$ & & & & & & & 3 & 17 \\
\hline c & & & & & & & 2 & 9 \\
\hline $\mathrm{D}$ & & & & & & & 2 & 15 \\
\hline $\mathrm{E}$ & & & & & & & 3 & 98 \\
\hline $\mathrm{F}$ & & & & & & & 3 & 90 \\
\hline G & & & & & & & 3 & 90 \\
\hline $\mathrm{H}$ & & & & & & & 3 & 92 \\
\hline 1 & & & & & & & 2 & 90 \\
\hline $\mathrm{J}$ & & & & & & & 3 & 90 \\
\hline $\mathrm{k}$ & & & & & & & 3 & 99 \\
\hline $\mathrm{L}$ & & & & & & & 3 & 115 \\
\hline $\mathrm{M}$ & & & & & & & 3 & 90 \\
\hline $\mathrm{N}$ & & & & & & & 4 & 90 \\
\hline
\end{tabular}

b

\begin{tabular}{|c|c|c|c|c|c|c|c|c|}
\hline \multirow{2}{*}{ Participant } & \multicolumn{2}{|c|}{ HIV-2 } & \multicolumn{3}{|c|}{ HIV-1 } & Frequency of reactivity to \\
& HIV-1/2 proteins & $\begin{array}{c}\text { Estimated time post } \\
\text { infection (days) }\end{array}$ \\
\hline A & & & & & & & 4 & 19 \\
\hline B & & & & & & & 3 & 17 \\
\hline C & & & & & & & 2 & 9 \\
\hline D & & & & & & & 2 & 15 \\
\hline E & & & & & & & 3 & 105 \\
\hline F & & & & & & & 3 & 193 \\
\hline G & & & & & & & 3 & 90 \\
\hline H & & & & & & & 4 & 97 \\
\hline I & & & & & & & 3 & 167 \\
\hline J & & & & & & & 3 & 97 \\
\hline K & & & & & & & 4 & 129 \\
\hline L & & & & & & & 3 & 92 \\
\hline M & & & & & & & 3 & 93 \\
\hline N & & & & & & & 4 & \\
\hline
\end{tabular}

C

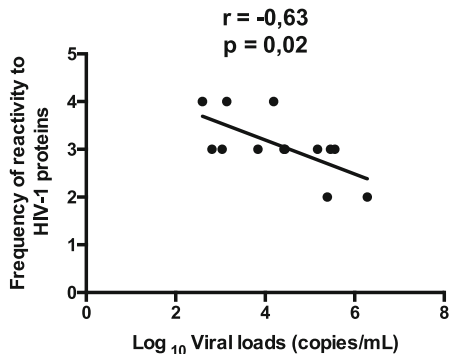

Fig. 1 Frequency of antibodies reactive to HIV-1 proteins in plasma from HIV early infected individuals. Serum samples from HIV infected individuals with early infection were collected for assessment of reactivity to HIV-1 proteins using the Geenius HIV-1/2 Confirmatory System. The reactivity of serum samples to HIV-1 proteins p31, gp160, p24 and gp 41 was recorded at seroconversion visit (a) and at time of PBMC collection (b). For each individual, the frequency of reactive bands on Geenius test, is indicated. c Correlation between the frequency of reactive bands and viral loads at PBMC collection visit

to cell staining, PBMC were allowed to recover overnight in $\mathrm{R} 10$ medium at $37{ }^{\circ} \mathrm{C}$ in an atmosphere of $7.5 \%$ $\mathrm{CO}_{2}$. Subsequently, PBMC were counted and washed in phosphate buffered saline (PBS). Cell viability was assessed by adding $50 \mu \mathrm{l}$ of the viability dye (fixable viability stain (FVS) 510 (BD, USA)) to one million PBMC. Finally, cells were washed again and stained for cell surface markers. Three eight-color panels were prepared per subject, each containing 500,000 cells. One panel was used to stain cell surface markers only and two other panels were used for combined staining of surface markers and transcription factors, FoxP3 and Helios, all following the instructions from the manufacturer. The FoxP3 buffer set from BD was used to fix and permeabilize PBMC for FoxP3 and Helios staining following manufacturer recommendations.
The following eight-color panels were used: (1) $\mathrm{CD} 3^{\mathrm{FTTC} /}$ $\mathrm{CD}_{5} \mathrm{RA}^{\mathrm{PerCP}} / \mathrm{HLADR}^{\mathrm{PE}-\mathrm{CY} 7} / \mathrm{CD} 38^{\mathrm{APC}} / \mathrm{CD}^{\mathrm{APC}-\mathrm{H} 7} /$ $\mathrm{CD} 4{ }^{\mathrm{V} 450}$ / FVS510 for assessment of levels of immune activation of CD4 and CD8 T cells; (2) $\mathrm{CD}^{\mathrm{A}} 5^{\mathrm{FITC}} / \mathrm{FoxP}^{\mathrm{PE}} /$ $\mathrm{CD} 49 \mathrm{~d}^{\mathrm{PerCP}} / \mathrm{CD} 25^{\mathrm{PE}-\mathrm{CY} 7} / \mathrm{B}^{\mathrm{APC}} / \mathrm{CD} 3^{\mathrm{APC}-\mathrm{H} 7} / \mathrm{CD} 4^{\mathrm{V} 450} /$ FVS510, and (3) $\mathrm{CD} 1^{\mathrm{FITC}} / \mathrm{FoxP}^{\mathrm{PE}} / \mathrm{CD}^{\mathrm{BTRA}}{ }^{\mathrm{PerCP}} /$ $\mathrm{CD}^{2} 5^{\mathrm{PE}-\mathrm{CY} 7} /$ Helios $^{\mathrm{APC}} / \mathrm{CD}^{\mathrm{APC}-\mathrm{H} 7} / \mathrm{CD}^{\mathrm{V} 450} / \mathrm{FV} 5510$ were used for co-expression analysis of lineage or activation markers and expression of HIV-1 co-receptors on classic Tregs. After staining, cells were fixed with 1X BD CellFix (BD, USA) and analyzed within $24 \mathrm{~h}$. The description of each monoclonal antibody is summarized in Additional file 1. Extensive titration experiments were performed on monoclonal antibodies prior to testing of participant samples.

A minimum of 100,000 events were acquired on FACSCanto II (Becton Dickinson (BD), USA) with Diva 
software version 8 (Becton Dickinson, USA). The BD Cytometer Setup \& Tracking (CST) beads and BD Comp beads were used to ensure consistency of results over time and for compensation, respectively. The postacquisition analyses, including compensation, were performed using the FlowJo software, version 10 (FlowJo LLC, USA). The fluorescence minus one (FMO) controls were used for definition of positivity applied to markers with continuous or dim levels of expression during post acquisition analysis. Representative plots, showing the gating strategy used for definition of $\mathrm{T}$ cells, including the classic Tregs and their phenotypes, are shown in Additional file 2 and Additional file 3.

\section{Statistical analysis}

Statistical analyses were performed using the software GraphPad Prism version $6.0 \mathrm{~h}$ (San Diego, CA). The Mann-Whitney test was used to test the heterogeneity among different groups. The analysis of correlations between two variables was performed by the Spearman Rank correlation. Difference or correlation with $p$-values less than 0.05 were considered statistically significant.

\section{Results}

Characterization of subjects with early HIV infection. An overview of characteristics of the study participants is shown in Table 1. In total, 14 early infected individuals were included in this sub-study, of whom seven were female. The median age was 21 years and none of the participants had received any HIV antiretroviral treatment at time of PBMC collection. The time between the last HIV negative test and first positive rapid test were 90 days (median) while the PBMC collections were performed 95 days (median) after infection. The median viral load at time of PBMC collection was $4.42 \log 10$ copies/mL. As expected, the viral load was inversely correlated with the frequency of antibody reactive bands to HIV-1 proteins $(r=-0.63 ; p=0.02)$ as shown in Fig. 1c. For some participants, the number of reactive bands increased from between the seroconversion visit and the time of PBMC collection (Fig. 1a and b).
CD8 T cell activation correlates with the frequency of reactive bands to HIV-1 proteins in peripheral blood of patients with early infection

It is well known that HIV infection and disease progression is associated with systemic immune activation. Tcell activation starts at the acute phase of HIV infection and persists during the chronic phase, even after initiation of highly effective antiretroviral therapy [25]. Both CCR5 and CCR3 participate in T cell activation and migration during the inflammatory process, and are expressed predominantly on memory Th1 cells [26].

CD8 T cell activation was high in HIV early-infected group as compared to the HIV negative control group $(p<0.0001)$, and correlated positively with viral load $(r=$ $0.73 ; p=0.008$ ) and inversely with the frequency of antibodies reactive to two or more HIV-1 proteins, namely p31, gp160, p24 and, gp4 ( $r=-0.59 ; p=0.03)$ (Fig. 2a-c). We found an increased proportion of CD8 T cell (CD3 $\left.{ }^{+} \mathrm{CD}^{+}\right)$expressing CXCR3 $(p=0.05)$ and CCR5 $(p=$ 0.002), as compared to controls (Fig. $2 \mathrm{~d}$ and e). However, the proportion of CD8 T cells expressing CCR5 and CXCR3 was not associated with either viral load ( $r=$ $0.01 ; p=0.9$ and $r=0.17 ; p=0.57$, respectively) or frequency of antibody responses against HIV-1 proteins $(r$ $=0.20 ; p=0.48$ and $r=-0.18 ; p=0.71$, respectively).

The activation profile of $\mathrm{CD} 4 \mathrm{~T}$ cell $\left(\mathrm{CD}^{+} \mathrm{CD}^{+}\right)$, measured by analyzing the co-expression of HLA-DR and CD38, was significantly higher in the HIV early infected group as compared to controls $(p=0.02)$. The proportions of both $\mathrm{CD} 4^{+} \mathrm{CD} 38^{+} \mathrm{HLADR}^{+}$and $\mathrm{CD} 4^{+} \mathrm{HLADR}^{\mathrm{High}}$ tended to correlate inversely with the frequency reactive bands of HIV proteins ( $r=$ $-0.45 ; p=0.12$ and $r=-0.66 ; p=0.01$, respectively) and with the absolute CD4 T cell counts $(r=-0.51 ; p$ $=0.07$ and $\mathrm{r}=-0.4 ; p=0.17$, respectively). However, no significant correlation was found between the CD4 $\mathrm{T}$ cell activation and viral load $(=0.34 ; p=0.26)$. We also found a positive correlation between the percentage of recent CD4 thymic emigrants, defined as CD3 ${ }^{+} \mathrm{CD} 4{ }^{+} \mathrm{CD} 31^{+} \mathrm{CD} 45 \mathrm{RA}{ }^{+}$, and the frequency of reactivity to $\mathrm{HIV}-1$ proteins $(r=0.6 ; p=0.04)$, but

Table 1 Characteristics of study groups

\begin{tabular}{|c|c|c|c|}
\hline & Early $\left(\mathrm{HIV}^{+}\right)$ & Chronic $\left(\mathrm{HIV}^{+}\right)$ & Control $\left(\mathrm{HIV}^{-}\right)$ \\
\hline $\mathrm{N}$ & 14 & 8 & 15 \\
\hline Median age (IQR) (years) & $21(20-24)$ & $23(21-33)$ & $20(19-24)$ \\
\hline $\operatorname{Sex}(F / M)$ & $7 / 7$ & $6 / 2$ & $10 / 5$ \\
\hline 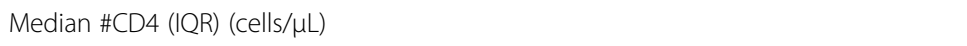 & $628(396-771)$ & $626(492-749)$ & 902 \\
\hline Median $\log _{10}$ viral load (IQR) (copies/mL) & $4.43(3.11-5.40)$ & $4.61(2.32-4.93)$ & N/A \\
\hline Median time before the last negative HIV rapid test and the first positive result (days) & 93 & $>270$ & N/A \\
\hline Participants with viral load detected or $>20$ copies/mL (N) & 14 & 4 & N/A \\
\hline Participants on ART (N) & 0 & 7 & N/A \\
\hline
\end{tabular}

$I Q R$ interquartile range, $M / F$ male/female, $N / A$ not applicable, $A R T$ Antiretroviral therapy 


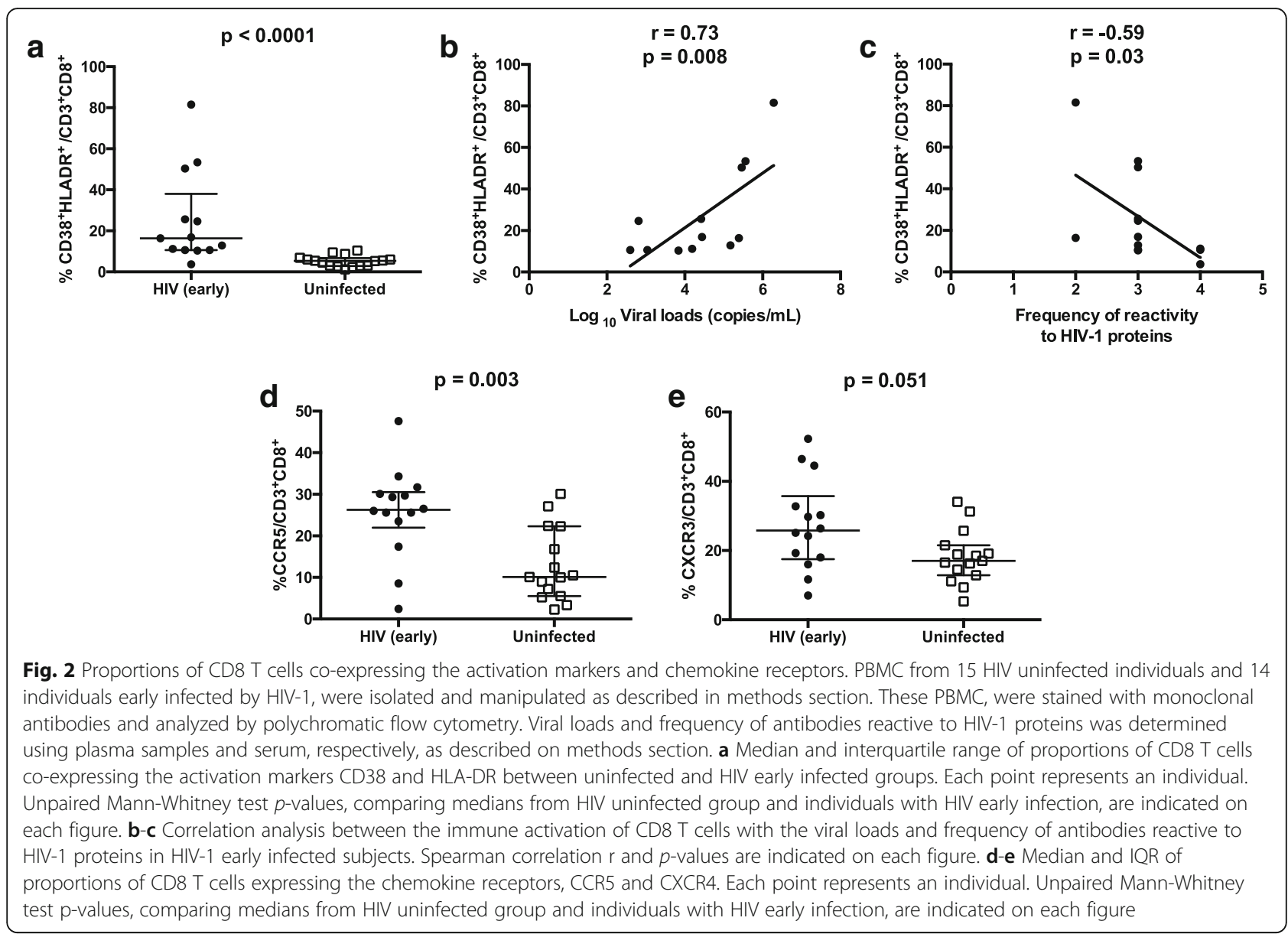

percentages did not differ between HIV early infected patients and controls $(p=0.45)$.

With regard the expression of chemokine receptors on CD4 T cells, we did not find significant differences of $\mathrm{CD}^{+}{ }^{+} \mathrm{CCR} 5^{+}(p=0.24)$ and $\mathrm{CD}^{+}{ }^{+} \mathrm{CXCR}^{+} \mathrm{T}$ cells $(p=0.97)$ expression levels between the two groups. In addition, the proportion of $\mathrm{CD}^{+} \mathrm{CCR}^{+}(p=0.24)$ and $\mathrm{CD}_{4}^{+} \mathrm{CXCR}^{+} \mathrm{T}$ cells did not correlate significantly with viral load $(r=-0.16 ; p=0.59$ and $r=$ $-0.16 ; \mathrm{p}=0.59$, respectively) or with the frequency of antibody response against HIV proteins $(r=0.15 ; p=$ 0.60 and $\mathrm{r}=0.15 ; p=0.60$, respectively).

\section{Proportions of classic CD4 ${ }^{+} \mathrm{CD} 25^{\mathrm{High}} \mathrm{FoxP}^{+}$Treg cells correlates with viral load, reactivity to HIV-1 proteins, and CD4 counts in HIV patients with early infection}

The absolute counts and percentages of classic Tregs was analyzed. We observed a decrease of absolute numbers of classic $\mathrm{CD} 4{ }^{+} \mathrm{CD} 25^{\mathrm{High}} \mathrm{FoxP}^{+}$Tregs in HIV early infected patients compared with control group $(p=0.02)$ but not with those with chronic infection. No difference was observed in proportion when compared with control group ( $p=0.60$ ) (Fig. 3a and b). However, the proportion of classic Tregs, in the HIV early infected group correlated positively with viral load $(r=0.8 ; p=0.002)$, the proportion of activated $\mathrm{CD}^{+} \mathrm{CD}^{+} 8^{+} \mathrm{HLADR}^{+}(r=0.68 ; p=0.03)$ cells, and absolute numbers of CD4 T cells $(r=-0.9 ; p=$ 0.0004) (Fig. 3c-e). Despite the absence of significant correlation between the frequency of Tregs and the frequency of bands reactive to HIV proteins $(r=-0.53 ; p=0.1)$, at time of PBMC collection, we found a significant correlation with the number of bands at seroconversion visit $(r=-0.67 ; p=0.03)$ (Fig. $3 f$ and $g$ ).

The absolute decrease of classic Tregs did not correlate with viral load $(r=0.21 ; p=0.53)$, frequency of antibodies reactive to HIV-1 proteins $(r=-0.26 ; p=0.43)$ nor total number of CD4 T cells $(r=-0.17 ; p=0.61)$.

\section{Increased expression of CCR5 and CXCR3 on classic CD4 ${ }^{+} \mathrm{CD} 25^{\text {High }} \mathrm{FoxP3}^{+}$Tregs in HIV patients with a recent infection} Chemokine receptor expression on Tregs can predict their function and their potential to accumulate in nonlymphoid tissues [27]. It has been shown that CXCR3 ${ }^{+}$ and $\mathrm{CCR}^{+}$Tregs are recruited to sites with ongoing Th1 inflammation [28, 29]. Furthermore, increased expression levels of CCR5 and integrin $\beta 7$ are associated 

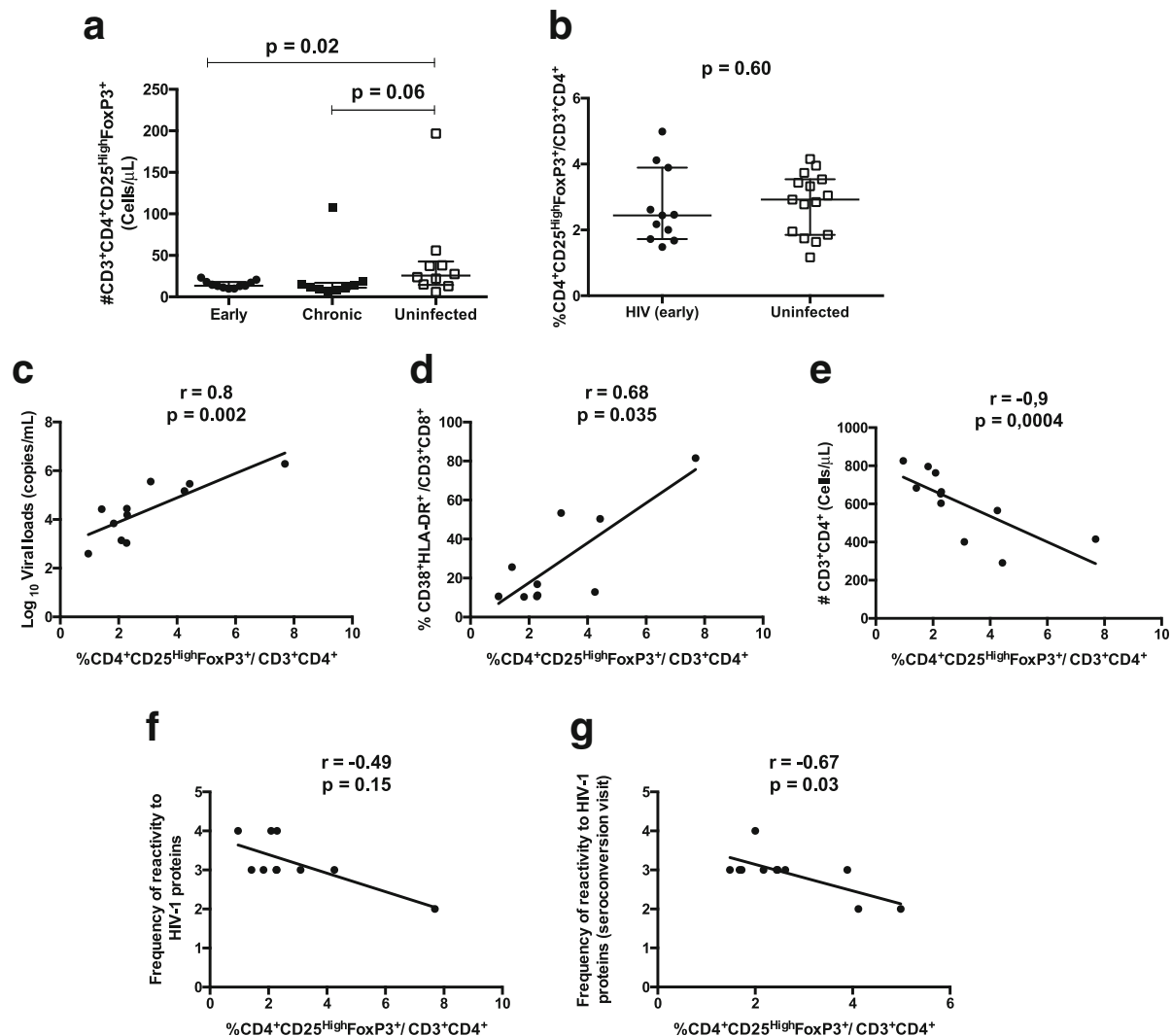

Fig. 3 Frequencies of Tregs and correlations with virologic and immunologic indicators. PBMC from HIV uninfected controls (15), HIV recently (11) and chronically (eight) infected patients, were isolated and manipulated as described in methods section. These PBMC were stained with monoclonal antibodies and analyzed by polychromatic flow cytometry. Viral loads and frequency of antibodies reactive to HIV-1 proteins were determined using plasma and serum samples, respectively, as described on methods section. $\mathbf{a}-\mathbf{b}$ Median and interquartile range for proportions and absolute counts of classic Tregs, CD4 ${ }^{+} \mathrm{CD} 25^{\text {High }}$ FoxP3, in study groups. Each point represents an individual. Unpaired Mann-Whitney test $p$-values comparing medians from controls and HIV infected groups are indicated on each figure. c-g Correlations between the proportions of classic CD4 ${ }^{+} \mathrm{CD} 25^{\mathrm{High}} \mathrm{FoxP} 3^{+}$Tregs with the viral loads, immune activation, absolute CD4 T cell counts and frequency of antibodies reactive to HIV-1 proteins at time of PBMC collections and at seroconversion visit. Each point corresponds to one individual. Spearman correlation $r$ and $p$-values are indicated on each figure

with higher susceptibility to HIV infection and poor immunological response [30-32].

We observed an increased proportion of CCR5 $(p=0.01)$ and CXCR3 $(\mathrm{p}=0.03)$ on classic Tregs in patients with a recent HIV infection as compared to controls (Fig. 4). However, the increased expression of CCR5 and CXCR3 on classic Tregs did not correlate with viral load, nor with reactivity to HIV-1 proteins or with T cell activation.

The proportion and absolute number of classic CD4 ${ }^{+} \mathrm{CD} 25^{\text {High }}{ }^{\text {FoxP }}{ }^{+}$Tregs expressing $\beta 7$ integrin did not differ between HIV patients and controls $(p=0.45$ and $p=0.22$ respectively). Their expression did not correlate with viral load, nor with frequency of antibodies reactive to HIV-1 proteins, $\mathrm{T}$ cell activation or with absolute numbers of CD4 $\mathrm{T}$ cells.

The proportion of Helios expressing Tregs correlates with HIV-1 viral loads and CD4 T cell absolute counts

It has been shown that co-expression of FoxP3 and Helios identifies Tregs that do not produce inflammatory cytokines [33]. In addition, it has also been shown that deletion of Helios contributes to progressive systemic immune activation [34]. We analyzed the proportion of classic $\mathrm{CD}^{+} \mathrm{CD} 25^{\mathrm{High}} \mathrm{FoxP}^{+}$Tregs expressing Helios (Fig. 5a) and found an inverse correlation between Tregs expressing Helios and viral load in early infection $(r=$ $-0.63 ; p=0.04$ ) (Fig. 5c). This correlation was preserved, when including chronically infected subjects with detectable viral loads $(r=-0.62 ; p=0.01)$ (Fig. $5 \mathrm{~d})$. In addition, the proportion of Tregs expressing Helios showed a trend to correlate positively with the recovery of CD4 T cells absolute counts, in early infected group $(r=0.6$; $p=0.056$ ). Furthermore, when adding data from progressive and chronically infected individuals with detectable viral loads, the correlation between Helios expressing Tregs and absolute CD4 $\mathrm{T}$ cell counts became significant $(r=0.56 ; p=0.03)$ (Fig. 5e). We also found tendencies to correlations, between proportions of Tregs expressing Helios in early infected patients with 

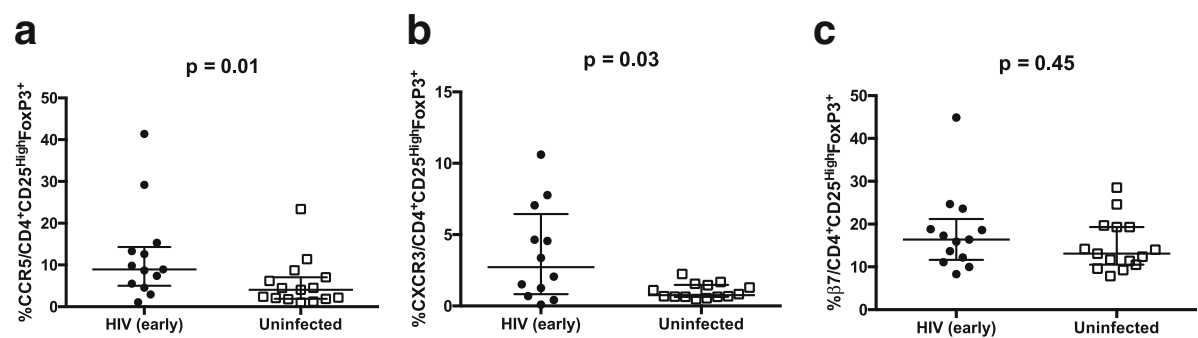

Fig. 4 Expression of chemokine receptors CCR5 and CXCR3, and $\beta 7$ integrin in classic Tregs. PBMC from 15 HIV uninfected individuals and 11 HIV-1 early infected individuals, were isolated and manipulated as described in methods section. These PBMC were stained with the following combination of monoclonal antibodies: CD195 $\mathrm{FTC} / \mathrm{FoXP3} 3^{\mathrm{PE}} / \mathrm{CD} 49 \mathrm{~d}^{\mathrm{PeCP}} / \mathrm{CD} 25^{\mathrm{PE}-\mathrm{CY} 7} / \beta 7^{\mathrm{APC}} / \mathrm{CD} 3^{\mathrm{APC}-\mathrm{H7}} / \mathrm{CD}^{\mathrm{V} 450} / \mathrm{FVS510}$. Data acquisition was performed on a flow cytometer (FACS CANTO II). Viral loads and frequency antibodies reactive to HIV-1 proteins was determined using plasma samples as described on methods section. a-c Median and interquartile range for proportions of CCR5, CXCR3 and $\beta 7$ expression on classic CD4 ${ }^{+}$CD25 $5^{\text {High }}$ FoxP3 ${ }^{+}$Tregs, in study groups. Each point represents an individual. Unpaired Mann-Whitney test p-values comparing medians from HIV uninfected controls and HIV infected group are indicated on each figure. Each point corresponds to one individual. p-values are indicated on each figure

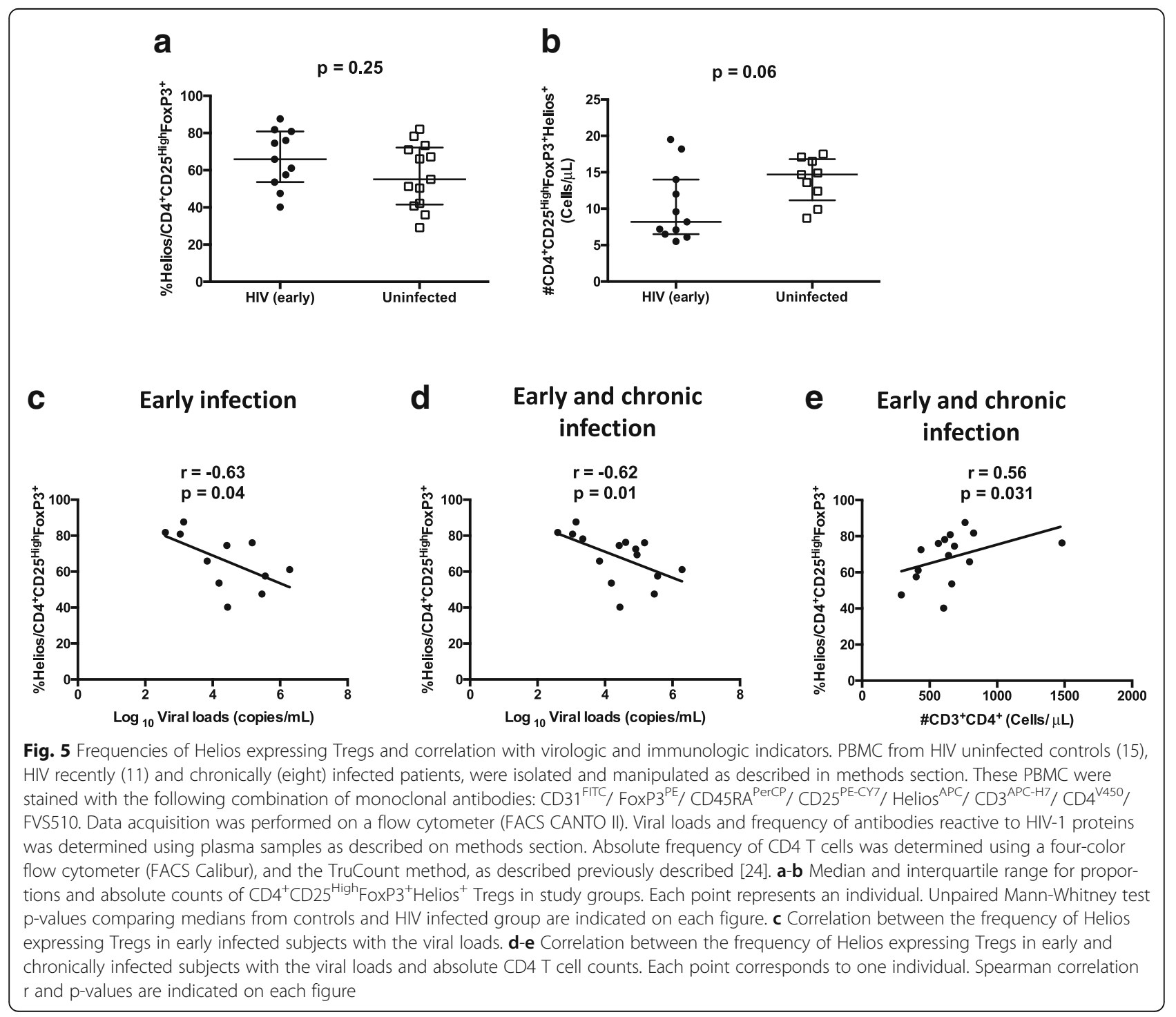


the proportions of activated CD8 T cells $(r=-0.48 ; p=$ $0.15)$ and frequency of antibodies reactive to HIV-1 proteins $(r=0.47 ; p=0.17)$. The absolute numbers of classic Tregs expressing Helios did not differ significantly between early infected patients with either controls $(p=0.24)$, despite the trend to a decrease of proportions in early infected patients $(p=0.06)$.

\section{Discussion}

Tregs regulate immune responses and prevent or downregulate exacerbated immune reactions by an array of mechanisms including suppression of $\mathrm{T}$ cell activation [35]. This characteristic of Tregs makes them an attractive target to treat inflammatory disorders but also to improve immunogenicity during vaccination against infectious diseases $[7,36,37]$. Tregs are expected to down-regulate immune activation after the acute phase of infection. However, this regulatory activity may also have a negative impact on development of effective antiHIV immune responses. It has been shown that depletion of regulatory $\mathrm{T}$ cells improve reactivation of virusspecific CD8 + T cells in chronic viral infections models such as in Friend retrovirus and in lymphocytic choriomeningitis virus (LCMV) infection [38-40].

During early stages of HIV infection, a massive depletion of CD4 T cells occurs, mainly from the gut associated lymphoid tissue (GALT), the preferential site of initial replication of the virus [41, 42]. Concomitantly, the structure of the GALT is compromised and passive microbial translocation occurs which is believed to drive or contribute to increased non-specific systemic immune activation [42]. We observed an absolute decrease of classic Tregs in patients with HIV early infection, as observed in previous studies [43-45]. However, despite the decrease of the CD4 $\mathrm{T}$ cell percentage, we did not find a concordant relative decrease of classic Tregs, suggesting that these cells are better preserved, at least during the early phase of HIV infection. We also found a strong but inverse correlation between Tregs percentages and absolute CD4 counts. Interestingly, high levels of T cell activation were seen in patients with higher percentages of classic Tregs. This may be explained by the fact that classic Tregs are effective in suppressing antigen-specific immune activation but not that of bystander immune activation, as observed in previous HIV studies [46].

Since classic Tregs are more effective in controlling antigen-specific immune responses, we evaluated their association with humoral anti-HIV immune responses. At the early stages of HIV infection, HIV-specific CD8 T cell responses have been shown to be critical, but insufficient to control viral replication [23]. The control of the initial viremia occurs at onset of antibody production to HIV proteins, although it has been suggested that these antibodies are less effective in virus neutralizing and mediating virus inhibition by antibody-dependent cellmediated cytotoxicity (ADCC) [47]. Here, for the first time, we suggest an involvement of Tregs delaying antibody response in HIV infection. We observed lower frequencies of antibodies reactive to HIV-1 proteins and lower CD4 counts at higher Tregs proportions. In addition, classic Tregs percentages correlated strongly and positively with HIV plasma viral loads. These observations suggest that classic Tregs contribute to the observed delayed onset of antibody production in HIV infection [48], which result in delayed control of viral replication.

The phenotype of Tregs can also predict their organotropism, their target cells, function and susceptibility to HIV infection [27-29, 31]. We assessed the frequency of CXCR3 and CCR5 chemokine receptor expression together with the expression of integrin $\beta 7$ and the transcription factor Helios. We found a relative increase of Tregs expressing CXCR3 and CCR5 in HIV positive patients with early infection. The proportion of both chemokine receptors was at least twice as high as in uninfected controls. In contrast, the relative and absolute abundance of Tregs expressing the integrin $\beta 7$ remained unchanged. Despite the higher proportions of CD4 cells expressing the HIV co-receptor CCR5, we did not detect any association between the percentage or absolute counts of CCR5 ${ }^{+}$Tregs on the one hand and the plasma viral load on the other. In previous studies, a higher content of HIV DNA was found in $\mathrm{CD}^{2} 5^{+} \mathrm{FoxP}^{+}$ memory $\mathrm{CD} 4 \mathrm{~T}$ cells as compared to $\mathrm{CD}^{2} 5^{-} \mathrm{FoxP} 3^{-}$ memory CD4 T cells [30]. However, the sequences of HIV DNA found in memory CD25 + FoxP3+ were not similar to those found in plasma virions [30]. Thus, although Tregs might be preferentially infected by HIV due to expression of the HIV co-receptor CCR5, they probably do not contribute significantly to the overall plasma viral load. Furthermore, it was shown that Tregs are resistant to HIV-1 as consequence of repression of HIV-LTR by FoxP3 [49].

The Helios marker is an ikaros family transcription factor, initially identified as marker of natural Tregs [50, 51]. Helios expression confers stability of phenotype, enhanced immunosuppressive function and increased survival in periphery $[34,52]$. Here we show for the first time a correlation between proportions of Helios expressing Tregs with a positive laboratorial outcome in adults with HIV early infection. We found that the frequency of Helios ${ }^{+}$Tregs remained preserved in patients with early infection, probably due their fitness compared to Tregs not expressing Helios. Interestingly, at higher expression levels of Helios ${ }^{+}$Tregs, lower viral loads and higher CD4 $\mathrm{T}$ cells counts were observed. These results suggest that these bona fide Tregs in addition to being preserved, might be involved in mechanisms controlling 
the viral replication, probably limiting the activation of $\mathrm{T}$ cells. Studies in mice showed that selective deletion of Helios in Tregs leads to slow, progressive systemic immune activation [34]. However, studies conducted in HIV infected children [51] revealed contradictory results regarding correlation of Helios + Tregs with viral loads and absolute CD4 counts. These discrepancies might be explained mainly due to different strategies for identification of Tregs. Since, here we evaluated Helios ${ }^{+}$Tregs as CD4 ${ }^{+} \mathrm{CD} 25^{\mathrm{High}} \mathrm{FoxP}^{+}{ }^{+} \mathrm{Helios}^{+}$rather than memory Tregs identified as $\mathrm{CD}^{+}{ }^{+} \mathrm{FoxP}^{+}{ }^{+} \mathrm{Helios}^{+} \mathrm{CD} 45 \mathrm{RO}^{+}$. In addition, the difference in ages and staging of HIV-1 infection may also contribute to the observed discrepancies.

The limitations of our study are the low sample size, evaluation of only four unique HIV-1 epitopes and the consequent lack of precise staging of the acute infection, based on Fiebig classification and absence of functional tests for assessing Tregs and antibodies functionality.

\section{Conclusions}

Our results suggest that in early HIV infection, classic Tregs do not contribute to the control of systemic T cell activation but rather may be linked to delayed appearance and possibly maturation of antibodies directed against HIV proteins, delaying the control of viral replication. However, highly suppressive Helios expressing Tregs may have a beneficial effect on mechanisms associated with control of viral replication in the periphery. Nevertheless, anti-inflammatory, antiviral and vaccine therapy trials could consider modulation of classic Tregs to evaluate the mechanistic impact of experimental interventions.

\section{Additional files}

Additional file 1: List of antibodies used and a brief description of the purpose. (DOCX $75 \mathrm{~kb}$ )

Additional file 2: Gating strategy for identification of CD4 and CD8 T cells and classic Tregs. (PPTX 6278 kb)

Additional file 3: FMO controls for CCR5 and CXCR3 expression, and definition of $\beta 7$ and Helios on Tregs. (PPTX $6115 \mathrm{~kb}$ )

\section{Abbreviations}

AIDS: Acquired Immunodeficiency Syndrome; CISPOC: Centro de Investigação e Treino em Saúde da Polana Caniço; CNBS: Mozambican National Committee on Bioethics in Health (Comité Nacional de Biotética em Saúde de Moçambique); DMSO: Dimethyl sulfoxide; FCS: Fetal calf serum; Foxp3: (Transcription factor) forkhead box P3; HAART: Highly active antiretroviral treatment; HBV: Hepatitis B virus; HCV: Hepatitis C virus; HIV1: Human immunodeficiency virus type 1; PBMC: Peripheral blood mononuclear cells; Tregs: Regulatory CD4 ${ }^{+} \mathrm{T}$ cells

\section{Acknowledgements}

We are thankful to all participants and the staff of the Centro de Investigação e Treino em Saúde da Polana Caniço, Department of Technological Platforms of the Instituto Nacional de Saúde. Special thanks to Alberto Machaze, Celso Castiano, Maria Enosse, Mirna Mutombene, Onélia Guiliche, Vania Monteiro, Victória Cumbane, Michelle Imbach, Leigh Anne Eller, and the RV363 team for their collaboration to this project.

\section{Funding}

The Department of Defense through cooperative agreements (W81XWH-07-2 0067 and W81XWH-11-0174) with the Henry M. Jackson Foundation for the Advancement of Military Medicine by the National Institute of Allergy and Infectious Diseases, NIH, through an interagency agreement with the U.S. Army (Y1-Al-2642-17) funded the establishment of the study cohort and acquisition of reagents for data collection. The Flanders Department of Foreign Affairs of the Flemish Government (BICMINS Project) funded the acquisition of reagents and software for data collection and analysis, respectively, under the PhD project of RMC.

\section{Availability of data and materials}

The datasets used and/or analyzed during the current study are available from the corresponding author on reasonable request.

\section{Authors' contributions}

RMC, EN and VM performed the experiment. RMC, IM, NB, CP, MR and NM participated in study coordination and contributed substantially reviewing the draft manuscript. RMC performed the data analysis, interpretation and drafted the manuscript. RMC, IJ and LK: designed the study, conceived the experiments and wrote the manuscript. All authors reviewed and approved the final version of the manuscript.

\section{Authors' information}

The views expressed are those of the authors and should not be construed to represent the positions of the Departments of the Army or Defense or the National Institutes of Health $(\mathrm{NIH})$.

\section{Ethics approval and consent to participate}

The regulatory authorities in Mozambique, United States of America and Belgium, the Mozambican National Ethics Committee (Comité Nacional de Bioética em Saúde) (IRB00002657), the Walter Reed Army Institute of Research (WRAIR) Institutional Review Board (IRB00000794), and the Medical Ethics Committee of the Institute of Tropical Medicine (IRB/AB/ac/007), Antwerp, Belgium, respectively, approved this study. A written informed consent was obtained for every participant and all consented to participate in this study.

Consent for publication

Not applicable.

Competing interests

The authors declare that they have no competing interests.

\section{Publisher's Note}

Springer Nature remains neutral with regard to jurisdictional claims in published maps and institutional affiliations.

\section{Author details}

${ }^{1}$ Instituto Nacional de Saúde, Maputo, Mozambique. ${ }^{2}$ Institute of Tropical Medicine, Department of Biomedical Sciences, Antwerp, Belgium. ${ }^{3}$ Department of Biomedical Sciences, University of Antwerp, Antwerp, Belgium. ${ }^{4}$ Military HIV Research Program, Walter Reed Army Institute of Research, MD, USA.

Received: 22 June 2017 Accepted: 6 December 2017

Published online: 16 December 2017

References

1. Sakaguchi S, et al. Regulatory T cells and immune tolerance. Cell. 2008;133(5):775-87.

2. Hartigan-O'Connor DJ, et al. Human CD4+ regulatory T cells express lower levels of the IL-7 receptor alpha chain (CD127), allowing consistent identification and sorting of live cells. J Immunol Methods. 2007;319(1-2):41-52

3. Nishimura $\mathrm{E}$, et al. Induction of antigen-specific immunologic tolerance by in vivo and in vitro antigen-specific expansion of naturally arising Foxp3 +CD25+CD4+ regulatory T cells. Int Immunol. 2004;16(8):1189-201.

4. Zheng SG, et al. Natural and induced CD4+CD25+ cells educate CD4 +CD25- cells to develop suppressive activity: the role of IL-2, TGF-beta, and IL-10. J Immunol. 2004;172(9):5213-21. 
5. Sugimoto $\mathrm{N}$, et al. Foxp3-dependent and -independent molecules specific for CD25+CD4+ natural regulatory T cells revealed by DNA microarray analysis. Int Immunol. 2006;18(8):1197-209.

6. Itoh $\mathrm{M}$, et al. Thymus and autoimmunity: production of CD25+CD4+ naturally anergic and suppressive $T$ cells as a key function of the thymus in maintaining immunologic self-tolerance. J Immunol. 1999;162(9):5317-26.

7. Boer MC, Joosten SA, Ottenhoff TH. Regulatory T-cells at the Interface between human host and pathogens in infectious diseases and vaccination. Front Immunol. 2015;6:217.

8. Thornton AM, et al. Expression of Helios, an Ikaros transcription factor family member, differentiates thymic-derived from peripherally induced Foxp3+ $T$ regulatory cells. J Immunol. 2010;184(7):3433-41.

9. Tao $\mathrm{JH}$, et al. Foxp3, regulatory $\mathrm{T}$ cell, and autoimmune diseases. Inflammation. 2017;40(1):328-39.

10. Issa F, Wood KJ. The potential role for regulatory T-cell therapy in vascularized composite allograft transplantation. Curr Opin Organ Transplant. 2014;19(6):558-65.

11. Tanaka A, Sakaguchi S. Regulatory T cells in cancer immunotherapy. Cell Res. 2017;27(1):109-18.

12. Miles B, Miller SM, Connick E. CD4 T follicular helper and regulatory cell dynamics and function in HIV infection. Front Immunol. 2016;7:659.

13. Jenabian MA, et al. Regulatory T cells in HIV infection: can immunotherapy regulate the regulator? Clin Dev Immunol. 2012;2012:908314.

14. Kinter AL, et al. CD25+ regulatory T cells isolated from HIV-infected individuals suppress the cytolytic and nonlytic antiviral activity of HIVspecific CD8+ T cells in vitro. AIDS Res Hum Retrovir. 2007;23(3):438-50.

15. Nobrega $\mathrm{C}$, et al. Longitudinal evaluation of regulatory T-cell dynamics on HIV-infected individuals during the first 2 years of therapy. AIDS. 2016;30(8):1175-86.

16. Rueda CM, et al. Incomplete normalization of regulatory t-cell frequency in the gut mucosa of Colombian HIV-infected patients receiving long-term antiretroviral treatment. PLoS One. 2013:8(8):e71062.

17. Rueda CM, et al. HIV-induced T-cell activation/exhaustion in rectal mucosa is controlled only partially by antiretroviral treatment. PLoS One. 2012;7(1): e30307

18. Venner $C M$, et al. Infecting HIV-1 subtype predicts disease progression in women of sub-Saharan Africa. EBioMedicine. 2016;13:305-14.

19. Chevalier MF, et al. CD4 T-cell responses in primary HIV infection: interrelationship with immune activation and virus burden. Front Immunol. 2016;7:395.

20. Robb ML, et al. Prospective study of acute HIV-1 infection in adults in East Africa and Thailand. N Engl J Med. 2016;374(22):2120-30.

21. Schuetz $A$, et al. Initiation of ART during early acute HIV infection preserves mucosal Th17 function and reverses HIV-related immune activation. PLoS Pathog. 2014;10(12):e1004543.

22. Baggaley R, et al. Beyond the 90-90-90: refocusing HIV prevention as part of the global HIV response. J Int AIDS Soc. 2016;19(1):21348

23. Cohen MS, et al. Acute HIV-1 infection. N Engl J Med. 2011;364(20):1943-54.

24. Matavele Chissumba R, et al. CD4(+)CD25(high) Treg cells in HIV/HTLV coinfected patients with neuropathy: high expression of Alpha4 integrin and lower expression of Foxp3 transcription factor. BMC Immunol. 2015;16:52.

25. Sandler NG, Sereti I. Can early therapy reduce inflammation? Curr Opin HIV AIDS. 2014;9(1):72-9.

26. Qin S, et al. The chemokine receptors CXCR3 and CCR5 mark subsets of T cells associated with certain inflammatory reactions. J Clin Invest. 1998; 101(4):746-54

27. Burzyn D, Benoist C, Mathis D. Regulatory T cells in nonlymphoid tissues. Nat Immunol. 2013:14(10):1007-13.

28. Koch MA, et al. The transcription factor T-bet controls regulatory $T$ cell homeostasis and function during type 1 inflammation. Nat Immunol. 2009:10(6):595-602.

29. Yurchenko $E$, et al. CCR5-dependent homing of naturally occurring CD4+ regulatory $T$ cells to sites of Leishmania major infection favors pathogen persistence. J Exp Med. 2006;203(11):2451-60.

30. Chachage M, et al. CD25+ FoxP3+ memory CD4 T cells are frequent targets of HIV infection in vivo. J Virol. 2016;90(20):8954-67.

31. Girard, A., et al., A high rate of beta7+ gut homing lymphocytes in HIV infected Immunogical non responders is associated with poor CD4 T cell recovery during suppressive HAART. J Acquir Immune Defic Syndr, 2016.

32. Mavigner $\mathrm{M}$, et al. Altered CD4+ $T$ cell homing to the gut impairs mucosal immune reconstitution in treated HIV-infected individuals. J Clin Invest. 2012;122(1):62-9.
33. Kim HJ, et al. Stable inhibitory activity of regulatory $T$ cells requires the transcription factor Helios. Science. 2015;350(6258):334-9.

34. Sebastian $\mathrm{M}$, et al. Helios controls a limited subset of regulatory $\mathrm{T}$ cell functions. J Immunol. 2016;196(1):144-55.

35. Lopez-Abente J, Correa-Rocha R, Pion M. Functional mechanisms of Treg in the context of HIV infection and the Janus face of immune suppression. Front Immunol. 2016;7:192

36. Lord JD. Promises and paradoxes of regulatory $T$ cells in inflammatory bowel disease. World J Gastroenterol. 2015:21(40):11236-45.

37. Wang YM, et al. Development and function of Foxp3(+) regulatory $T$ cells. Nephrology (Carlton). 2016;21(2):81-5.

38. Penaloza-MacMaster $P$, et al. Interplay between regulatory T cells and PD-1 in modulating T cell exhaustion and viral control during chronic LCMV infection. J Exp Med. 2014;211(9):1905-18.

39. Dietze KK, et al. Combining regulatory $T$ cell depletion and inhibitory receptor blockade improves reactivation of exhausted virus-specific CD8+ T cells and efficiently reduces chronic retroviral loads. PLoS Pathog. 2013: 9(12):e1003798.

40. Zelinskyy G, Werner T, Dittmer U. Natural regulatory T cells inhibit production of cytotoxic molecules in CD8(+) T cells during low-level friend retrovirus infection. Retrovirology. 2013;10:109.

41. Mudd JC, Brenchley JM. Gut mucosal barrier dysfunction, microbial Dysbiosis, and their role in HIV-1 disease progression. J Infect Dis. 2016; 214(Suppl 2):S58-66.

42. Sattentau Q. HIV's gut feeling. Nat Immunol. 2008;9(3):225-7.

43. Presicce $P$, et al. Frequency of circulating regulatory $T$ cells increases during chronic HIV infection and is largely controlled by highly active antiretroviral therapy. PLoS One. 2011;6(12):e28118.

44. Shaw JM, et al. Increased frequency of regulatory $T$ cells accompanies increased immune activation in rectal mucosae of HIV-positive noncontrollers. J Virol. 2011:85(21):11422-34.

45. Wang $W H$, et al. High frequency of regulatory $T$ cells among HIV type 1infected men who have sex with men correlates with disease progression. Chin Med J. 2013;126(11):2054-61.

46. $\mathrm{Li} \mathrm{C}$, et al. Functional characterization of $\mathrm{HLA}-\mathrm{G}(+)$ regulatory $\mathrm{T}$ cells in $\mathrm{HIV}-1$ infection. PLoS Pathog. 2013;9(1):e1003140.

47. Tomaras GD, et al. Initial B-cell responses to transmitted human immunodeficiency virus type 1: virion-binding immunoglobulin M (IgM) and IgG antibodies followed by plasma anti-gp41 antibodies with ineffective control of initial viremia. J Virol. 2008;82(24):12449-63.

48. Tomaras GD, Haynes BF. HIV-1-specific antibody responses during acute and chronic HIV-1 infection. Curr Opin HIV AIDS. 2009:4(5):373-9.

49. Selliah N, et al. FOXP3 inhibits HIV-1 infection of CD4 T-cells via inhibition of LTR transcriptional activity. Virology. 2008:381(2):161-7.

50. Muto S, et al. Clinical significance of expanded Foxp3(+) Helios(-) regulatory T cells in patients with non-small cell lung cancer. Int J Oncol. 2015;47(6):2082-90.

51. Khaitan A, et al. FOXP3+Helios+ regulatory $T$ cells, immune activation, and advancing disease in HIV-infected children. J Acquir Immune Defic Syndr. 2016;72(5):474-84

52. Elkord E. Helios should not be cited as a marker of human thymus-derived Tregs. Commentary: Helios(+) and Helios(-) cells coexist within the natural FOXP3(+) T regulatory cell subset in humans. Front Immunol. 2016;7:276.

\section{Submit your next manuscript to BioMed Central and we will help you at every step:}

- We accept pre-submission inquiries

- Our selector tool helps you to find the most relevant journal

- We provide round the clock customer support

- Convenient online submission

- Thorough peer review

- Inclusion in PubMed and all major indexing services

- Maximum visibility for your research

Submit your manuscript at www.biomedcentral.com/submit 